\title{
The Impact of Kitchen and Food Service Preparation Practices on the Volatile Aroma Profile in Ripe Tomatoes: Effects of Refrigeration and Blanching
}

\author{
Libin Wang \\ U.S. Horticultural Research Laboratory, Agriculture Research Service, U.S. \\ Department of Agriculture, 2001 South Rock Road, Fort Pierce, FL 34945; \\ and Nanjing Agricultural University, Nanjing, Jiangsu 210095, China
}

Elizabeth A. Baldwin

U.S. Horticultural Research Laboratory, Agriculture Research Service, U.S. Department of Agriculture, 2001 South Rock Road, Fort Pierce, FL 34945

Zhifang Yu
Nanjing Agricultural University, Nanjing, Jiangsu 210095, China

Jinhe Bai ${ }^{1}$

U.S. Horticultural Research Laboratory, Agriculture Research Service, U.S. Department of Agriculture, 2001 South Rock Road, Fort Pierce, FL 34945

Additional index words. Solanum lycopersicum, aromatic volatile, blanching, refrigeration, electronic nose

\begin{abstract}
Both refrigeration and blanching of red-stage tomatoes are common practices in Japan home kitchens and in food service operations. However, little is reported on the impact of such practices on aroma profiles in tomato fruits. In this study, ' $\mathrm{FL}$ 47' tomatoes at red stage were dipped in $50{ }^{\circ} \mathrm{C}$ hot water for 5 minutes or exposed to $5{ }^{\circ} \mathrm{C}$ for 4 days to simulate consumer handling of tomato in food service or home kitchens, respectively. Of the 42 volatile compounds detected, refrigeration generally suppressed production of aldehydes, alcohols, oxygen-containing heterocyclic compounds, and nitrogen- and oxygen-containing heterocyclic compounds, including the following abundant and/or important volatiles: pentanal, 3-methylbutanal, 2-methylbutanal, hexanal, cis-3-hexenal, trans-2-hexenal, 2phenylacetaldehyde, pentanol, 3-methylbutanol, 2-phenylethanol, 1-penten-3-one, geranial, and geranylacetone. On the other hand, the production of aldehydes, alcohols, hydrocarbons, oxygen-containing heterocyclic compounds, and nitrogen- and oxygencontaining heterocyclic compounds was reduced by blanching, associated with low concentrations of 2-methylbutanal, pentanal, cis-3-hexenal, trans-2-hexenal, 2-phenylacetaldehyde, pentanol, 2-methylbutanol, and 2-phenylethanol. These results indicate that a short blanching or refrigeration of tomatoes substantially impacts tomato aroma quality.
\end{abstract}

Tomato, one of the most popular vegetables in the American diet (Chun et al., 2005), is an excellent source of antioxidants, and has scientifically been proven to be an anti-

\footnotetext{
Received for publication 2 June 2015. Accepted for publication 17 July 2015.

We thank the financial support to the experiment from China Scholarship Council (201306850049), Postgraduate Program in Jiangsu Province (CXLX13_267), and the Big Red Tomato Packers, Fort Pierce, FL. Mention of a trademark or proprietary product is for identification only and does not imply a guarantee or warranty of the product by the U.S. Department of Agriculture. The U.S. Department of Agriculture prohibits discrimination in all its programs and activities on the basis of race, color, national origin, gender, religion, age, disability, political beliefs, sexual orientation, and marital or family status.

${ }^{1}$ Corresponding author. E-mail: jinhe.bai@ars.usda. gov.
}

cancer agent (Guil-Guerrero and RebollosoFuentes, 2009). Aroma, which is produced by a complex mixture of volatile compounds, plays an important role in the perception and acceptability of tomato products by consumers (El Hadi et al., 2013). Although more than 400 volatiles have been identified in the ripening tomato fruit, only 16 are reported to have positive log odor units, which is calculated from the ratio of the concentration of a component in a food to its odor threshold, and substantially contribute to tomato aroma, including cis-3hexenal, $\beta$-ionone, hexanal, $\beta$-damascenone, 1-penten-3-one, 3-methylbutanal, trans-2-hexenal, 2-isobutylthiazole, 1-nitro-2-phenylethane, trans2-heptenal, 2-phenylacetaldehyde, 6-methyl-5hepten-2-one, cis-3-hexenol, 2-phenylethanol, 3-methylbutanol, and methyl salicylate (Buttery, 1993). However, volatile compounds with negative odor units also may contribute to tomato aroma as background notes (Baldwin et al., 2000). Therefore, aroma models, based on concentrations and odor thresholds of individual volatiles, do not account for synergistic and antagonistic interactions that may occur in tomato fruit (Tieman et al., 2012).

Over the past 50 years, a significant dropoff in tomato aroma has been noticed by consumers, which is a major source of consumer complaints (Klee, 2010). In addition, breeding programs, which have made cheaper and year-round produce available, and have done so at the expense of aroma quality (Maul et al., 2000). Furthermore, inappropriate preor postharvest practices such as harvest maturity, application of plant growth regulators, and storage temperature/atmosphere have been shown to cause aroma loss in tomato fruit as well (Wang et al., 2015a). Like many other tropical and subtropical horticultural crops, tomato is sensitive to low temperature stress (McDonald et al., 1999). Under the current marketing system, fruit usually are harvested at the mature green stage and shipped at low temperature to slow ripening and prevent fruit losses due to bruising and decay, thereby extending storage life. When mature green tomatoes are stored at $13{ }^{\circ} \mathrm{C}$ for longer than 2 weeks or at $5^{\circ} \mathrm{C}$ for longer than $7 \mathrm{~d}$ before ripening at $20{ }^{\circ} \mathrm{C}$, a series of physiological/biochemical responses are activated that impair the fruit, including failure to develop full color and flavor, water-soaking, surface pitting, and susceptibility to Alternaria rot and other decay (Ding et al., 2002; Gross et al., 2004; Luengwilai and Beckles, 2010; Saltveit and Morris, 1990). Internal chilling injury (CI) in the form of aroma loss usually takes place in advance of visual CI symptoms (Maul et al., 2000). Our previous research showed impacts of chilling on flavor loss of mature green tomatoes: exposure of ' $\mathrm{FL} \mathrm{47'}$ tomato to $5{ }^{\circ} \mathrm{C}$ for $4 \mathrm{~d}$ did not cause any visual chilling symptoms following ripening at $20{ }^{\circ} \mathrm{C}$. However, a $51 \%$ reduction in aroma volatiles occurred, with the highest reduction in terpene volatiles followed by aldehydes, alcohols, esters, ketones, and acids (Wang et al., 2015b). Meanwhile, the production of seven key volatile compounds suggested by Klee (2010) was downregulated after the chilling exposure, including 6-methyl-5-hepten2-one, $\beta$-ionone, trans-2-hexenal, hexanal, 2phenylethanol, and 2-methylbutanal (Wang et al., 2015a). Furthermore, Bai et al. (2011) found that chilling-induced inhibition of tomato $\mathrm{C} 6$ volatile production may be due to downregulation of gene expression, and subsequent reduction of human pancreatic lipase (HPL) and alcohol dehydrogenases $(\mathrm{ADH})$ enzyme activities in the oxylipin pathway.

Heat treatment has been shown to be an effective method to sanitize the tomato and other fruit surfaces by reducing microbes. In addition, heat treatments can disinfect insects, delay ripening, and alleviate pathological and physiological disorders (Bai et al., 2004; Lurie, 1998; Plotto et al., 2003). However, a detrimental effect of heat 
treatment is aroma loss evidenced in many fruits including tomatoes (Bai et al., 2004, 2011; Lurie, 1998). Immersion of red tomato fruits ('Tasti-Lee' and 'Sanibel') in $52{ }^{\circ} \mathrm{C}$ hot water for $15 \mathrm{~min}$ inhibited $\mathrm{C} 6$ volatile production, possibly owning to the suppressed HPL and ADH activities (Bai et al., 2011). On the other hand, pretreatment with heat is a postharvest handling tool used to reduce CI in tomatoes. Tomatoes, pretreated at the mature green stage with either hot water $\left(42^{\circ} \mathrm{C}\right.$ for $\left.1 \mathrm{~h}\right)$ or hot air $\left(38^{\circ} \mathrm{C}\right.$ for $48 \mathrm{~h}$ ), did not suffer external CI after exposure to cold temperature (McDonald et al., 1996), and had less volatile flavor loss at $2{ }^{\circ} \mathrm{C}$ storage than those treated without prechilling heat treatment (McDonald et al., 1999). Previously, we reported that $52{ }^{\circ} \mathrm{C}$ hot water treatment for $5 \mathrm{~min}$ greatly alleviated chilling-induced volatile losses; however, the heat treatment itself inhibited the production of alcohols and acids in mature green ' $\mathrm{FL} \mathrm{47}$ ' tomatoes along with lower levels of $\beta$-ionone, 2-methylbutanal, 3-methylbutanol, and 2-phenylethanol (Wang et al., 2015b). Nevertheless, the fate of tomatoes at the end of the journey from farm to fork is the consumer, and how the consumer handling of tomatoes at home affects tomato flavor has not been well studied.

Refrigeration of tomatoes is a common consumer practice in home kitchens and blanching of fruit including tomatoes is common for Japanese consumers and in some food service operations. Refrigeration has been thought to slow fruit ripening and senescence, reduce microbial growth, and extend the storage time of tomato fruits (de Castro et al., 2006). The use of $50{ }^{\circ} \mathrm{C}$ or higher temperature for a few minutes (blanching) has been used in food service companies and kitchens to reduce microbial loads and inactivate deleterious enzymes (Castro et al., 2008). In Japan, a $50{ }^{\circ} \mathrm{C}$ dipping for up to $30 \mathrm{~min}$ has been suggested for fruits, vegetables, meat, and fish washing, which is believed to improve food flavor, but there is a lack of scientific evidence (Hirayama, 2012). Little is reported on the impact of such practices on tomato aroma quality. In this research, 'FL 47' tomatoes at full red stage were dipped in $50{ }^{\circ} \mathrm{C}$ hot water for $5 \mathrm{~min}$ or exposed to $5{ }^{\circ} \mathrm{C}$ for $4 \mathrm{~d}$ to simulate home kitchen practices. A combination of biochemical and physiochemical analysis was conducted to determine the impact of food service or kitchen practices on tomato aroma quality.

This article is one in a series of articles on postharvest flavor loss in tomato fruit. The previous two publications addressed how hot water pretreatment alleviates chillinginduced volatile loss (Wang et al., 2015a), and how methyl salicylate pretreatment alleviates chilling-induced volatile loss (Wang et al., 2015b). Mature green tomatoes were used for both experiments, and they were subjected to simulate the industrial storage and transportation conditions. In this article, we focused on the consumer-end temperature control- the fruit were treated after reaching edible maturity and right before serving. The objective was to provide consumers with information on how their kitchen practices influence tomato flavor quality.

\section{Materials and Methods}

Plant materials. Uniform and defect-free tomato fruits (60) at red stage (USDA, 1997), average $a^{*}$ value $\approx 18.7$, with an average weight of $281.4 \mathrm{~g}$, were purchased from a local grocery store on 6 Nov. 2014. The original volatile profile of the tomato fruit was listed in Table 1. Fruit were divided into three treatments: 1$)$ refrigerated at $5{ }^{\circ} \mathrm{C}$ for $4 \mathrm{~d}, 2$ ) kept at $20^{\circ} \mathrm{C}$ for $4 \mathrm{~d}$ and then dipped in $50{ }^{\circ} \mathrm{C}$ hot water for $5 \mathrm{~min}$, and 3 ) untreated control, continuously kept at $20{ }^{\circ} \mathrm{C}$ for $4 \mathrm{~d}$. The $\mathrm{a}^{*}$ values of fruit immediately after treatments were 19.1, 21.1, and 22.0, respectively. Fifteen out of 20 fruits per treatment, uniformly ripened during temperature treatments, were then selected and further divided into five replicates with three fruit per replicate. For sampling, pericarp tissue was taken with a sharp stainless steel knife, immersed in liquid $\mathrm{N}_{2}$, fractured into roughly $0.5-\mathrm{cm}$ diameter pieces, and then stored at $-80{ }^{\circ} \mathrm{C}$.

Headspace gas chromatography volatile analysis. Volatile analysis was conducted by headspace, solid phase microextraction, and gas chromatography-mass spectrometry system (HS-SPME-GC-MS), following the method of Wang et al. (2015b). Frozen pericarp tissue was ground to powder under liquid nitrogen and $4.3 \mathrm{~g}$ of powder, together with $1.7 \mathrm{~mL}$ of saturated calcium chloride $\left(\mathrm{CaCl}_{2}\right)$ solution were transferred to a $20-\mathrm{mL}$ vial and sealed with Teflon-lined septa. For headspace analysis, the homogenized samples were incubated for $30 \mathrm{~min}$ at $40{ }^{\circ} \mathrm{C}$, after which a 2-cm SPME fiber $(50 / 30 \mu \mathrm{m} \mathrm{DVB} /$ Carboxen/PDMS; Supelco, Bellefonte, PA) was exposed to the headspace for another $30 \mathrm{~min}$ at $40{ }^{\circ} \mathrm{C}$. After exposure, the SPME fiber was inserted into the injector of a GC-MS (Model 6890, Agilent, Santa Clara, CA) to desorb the extract for $15 \mathrm{~min}$ at $250{ }^{\circ} \mathrm{C}$. The GC-MS equipment and settings were: DB- 5 (60 m length, $0.25 \mathrm{~mm}$ i.d., $1.00 \mu \mathrm{m}$ film thickness; J\&W Scientific, Folsom, CA) columns, coupled with a 5973 N MS detector (Agilent). The column oven was programmed to increase at $4{ }^{\circ} \mathrm{C} \cdot \mathrm{min}^{-1}$ from the initial 40 to $230^{\circ} \mathrm{C}$, then ramped up at $100{ }^{\circ} \mathrm{C} \cdot \mathrm{min}^{-1}$ to $260{ }^{\circ} \mathrm{C}$ and kept for 11.70 min for a total run time of $60 \mathrm{~min}$. Helium was used as carrier gas at flow rate of $1.5 \mathrm{~mL} \cdot \mathrm{min}^{-1}$. Inlet, ionizing source, and transfer line were kept at 250 , 230 , and $280{ }^{\circ} \mathrm{C}$, respectively. Mass units were monitored from 30 to $250 \mathrm{~m} / \mathrm{z}$ and ionized at $70 \mathrm{eV}$. Data were collected using the ChemStation G1701 AA data system (Hewlett-Packard, Palo Alto, CA). A mixture of C-5 to C-18 n-alkanes was run at the beginning of each day to calculate retention indices (RIs). Volatile compounds were identified by comparison of their mass spectra with library entries (NIST/EPA/NIH Mass
Spectral Library, version 2.0d; National Institute of Standards and Technology, Gaithersburg, MA), as well as by comparing RI with authentic standard aroma compounds purchased from Sigma-Aldrich (St. Louis, MO) or Fluka Chemical Corporation (Buchs, Switzerland).

Quantification was conducted by using a peak area vs. concentration curve built by serially diluted five-point standard solutions (Baldwin et al., 2009). In brief, a standard compound was dissolved in pure methanol and the mixture was then introduced into a deodorized tomato homogenate. The range of concentrations in the standard curve for each compound covers the concentrations found in the samples.

Headspace electronic nose analysis. For sample preparation, $2.15 \mathrm{~g}$ frozen pericarp tissue ground to powder under liquid nitrogen, together with $0.85 \mathrm{~mL}$ of saturated $\mathrm{CaCl}_{2}$ solution were transferred to a $10-\mathrm{mL}$ vial and sealed with Teflon-lined septa before analysis.

For electronic nose (e-nose) analysis, a FOX 4000 system (Alpha MOS, Toulouse, France) was used, fitted with 18 metal oxide gas sensors, some with coated surfaces (Baldwin et al., 2012). The electrical output from the sensors was measured at 0.5 -s intervals. Samples were incubated in an agitator at $500 g_{n}$ and $40{ }^{\circ} \mathrm{C}$ for $2 \mathrm{~min}$ before the headspace sample $(500 \mu \mathrm{L})$ was taken from the vial and injected into the e-nose. The carrier gas was pure air with a flow rate of 150 $\mathrm{mL} \cdot \mathrm{min}^{-1}$. The e-nose data acquisition program was a 2-min sampling time followed by an 18-min delay between samples for sensor recovery.

Extraction and assay of HPL and protein. Extraction and assay of the enzyme HPL were carried out according to Bai et al. (2011) with some modification. A 96-well microplate reader (Model SynergHT, BioTek, Winooski, VT) was used for all analyses. Tris(hydroxymethyl)aminomethane, soybean type I-B lipoxidase, yeast $\mathrm{ADH}$, linoleic acid, $\beta$-Nicotinamide adenine dinucleotide dehydrogenase (NADH), sorbitol, $\mathrm{MgCl}_{2}$, polyvinylpyrrolidone (PVP), dithiothreitol (DTT), phenylmethyls $\mu$ lfonyl fluoride (PMSF), benzamidine, aminocaproic acid, sodium tetraborate, and Tween 20 were purchased from Sigma-Aldrich (St. Louis, MO). Glycerol, boric acid, sodium phosphate monobasic, sodium phosphate dibasic, and sodium hydroxide were purchased from J.T. Baker Inc. (Philipsburg, NJ).

Extraction of enzyme and protein: the composition of the homogenization buffer was $150 \mathrm{~mm}$ Tris- $\mathrm{HCl}(\mathrm{pH} 8.0)$, including $250 \mathrm{~mm}$ sorbitol, $10 \mathrm{~mm} \mathrm{MgCl}, 1 \%$ glycerol (v/v), 0.2\% PVP (w/v), $5 \mathrm{~mm}$ DTT and the following protease inhibitors: $0.1 \mathrm{~mm}$ PMSF, $0.1 \mathrm{~mm}$ benzamidine, and $5 \mathrm{~mm}$ aminocaproic acid. Frozen pericarp tissue $(5.0 \mathrm{~g})$ were ground in liquid nitrogen to the powder followed by the addition $5.0 \mathrm{~mL}$ homogenization buffer. After shaking and filtration through two layers of Mira cloth (Calbiochem, La Jolla, $\mathrm{CA})$, the homogenate was centrifuged for 
Table 1. Impact of refrigeration and blanching on volatile profile in full ripe 'FL 47' tomato fruits. ${ }^{2}$

\begin{tabular}{|c|c|c|c|c|c|c|c|c|}
\hline \multirow[b]{2}{*}{ Compounds } & \multirow{2}{*}{$\begin{array}{l}\text { Retention } \\
\text { index (RI) }\end{array}$} & \multirow{2}{*}{$\begin{array}{c}\text { Odor } \\
\text { description }^{y}\end{array}$} & \multirow{2}{*}{$\begin{array}{l}\text { Odor threshold } \\
\text { in water }\left(\mathrm{mg} \cdot \mathrm{L}^{-1}\right)^{\mathrm{x}}\end{array}$} & \multirow[b]{2}{*}{ Original } & \multicolumn{3}{|c|}{ Concn $\left(\mathrm{mg} \cdot \mathrm{L}^{-1}\right)$} & \multirow[b]{2}{*}{ LSD } \\
\hline & & & & & Control & Refrigeration & Blanching & \\
\hline 2-methylpropanal & 565 & Pungent, malt, green & $8.2-19$ & 0.064 & $0.074 \mathrm{a}^{\mathrm{v}}$ & $0.040 \mathrm{~b}$ & $0.028 \mathrm{~b}$ & 0.015 \\
\hline Butanal & 587 & Pungent, green & 0.009 & 0.038 & $0.1329 \mathrm{a}$ & $0.029 \mathrm{~b}$ & $0.043 \mathrm{~b}$ & 0.059 \\
\hline 2-methylbutanal ${ }^{\mathrm{w}}$ & 644 & Cocoa, almond & 0.003 & 0.57 & $1.01 \mathrm{a}$ & $0.28 \mathrm{~b}$ & $0.38 \mathrm{~b}$ & 0.16 \\
\hline Pentanal $^{\mathrm{w}}$ & 673 & Almond, malt, pungent & 0.012 & 0.0027 & $0.0197 \mathrm{a}$ & $0.0041 \mathrm{c}$ & $0.0085 \mathrm{~b}$ & 0.0037 \\
\hline 2-methyl-2-butenal & 716 & Green, fruit & 0.5 & 0.2596 & $0.1434 \mathrm{a}$ & $0.0036 \mathrm{c}$ & $0.0612 \mathrm{~b}$ & 0.0217 \\
\hline Trans-2-hexenal ${ }^{\mathrm{w}}$ & 825 & Apple, green & 0.017 & 2.46 & $2.62 \mathrm{a}$ & $0.19 \mathrm{c}$ & $1.21 \mathrm{~b}$ & 0.44 \\
\hline Heptanal & 870 & Fat, citrus, rancid & 0.003 & 0.0029 & $0.0043 \mathrm{a}$ & $0.0039 \mathrm{a}$ & $0.0030 \mathrm{a}$ & 0.0019 \\
\hline Trans, trans-2, 4-hexadienal & 883 & Nut, fat & 0.06 & 4.177 & $3.697 \mathrm{a}$ & $0.029 \mathrm{c}$ & $0.748 \mathrm{~b}$ & 0.217 \\
\hline Benzaldehydew $^{w}$ & 961 & Almond, burnt sugar & 0.35 & 0.0023 & $0.0019 \mathrm{a}$ & $0.0020 \mathrm{a}$ & $0.0015 \mathrm{a}$ & 0.0006 \\
\hline Octanal & 965 & Fat, soap, lemon, green & 0.0007 & 0.00067 & $0.00083 \mathrm{a}$ & $0.00062 \mathrm{a}$ & $0.00066 \mathrm{a}$ & 0.0007 \\
\hline Phenylacetaldehyde w & 1012 & Hawthorne, honey, sweet & 0.004 & 2.57 & $4.20 \mathrm{a}$ & $1.68 \mathrm{~b}$ & $1.22 \mathrm{~b}$ & 0.81 \\
\hline Nonanal & 1056 & Fat, citrus, green & 0.001 & 0.00062 & $0.00083 \mathrm{a}$ & $0.00046 \mathrm{~b}$ & $0.00041 \mathrm{~b}$ & 0.0002 \\
\hline 3-methylbutanol ${ }^{\mathrm{w}}$ & 705 & Whiskey, malt, burnt & $0.25-0.3$ & 0.023 & $0.033 \mathrm{a}$ & $0.014 \mathrm{~b}$ & $0.031 \mathrm{a}$ & 0.005 \\
\hline 2-methylbutanol ${ }^{\mathrm{w}}$ & 708 & Wine, onion & $0.25-0.3$ & 0.73 & $0.59 \mathrm{a}$ & $0.61 \mathrm{a}$ & $0.34 \mathrm{~b}$ & 0.058 \\
\hline Pentanol $^{w}$ & 738 & Balsamic & 4 & 0.0225 & $0.0588 \mathrm{a}$ & $0.00398 \mathrm{~b}$ & $0 \mathrm{~b}$ & 0.0159 \\
\hline 4-methylpentanol & 804 & Pungent & $0.82-4.1$ & 0.031 & $0.0185 \mathrm{a}$ & $0 \mathrm{c}$ & $0.0073 \mathrm{~b}$ & 0.0027 \\
\hline 3-methylpentanol & 813 & Pungent & $0.83-4.1$ & 0.0171 & $0.0201 \mathrm{a}$ & $0.0200 \mathrm{a}$ & $0.0080 \mathrm{~b}$ & 0.0034 \\
\hline 6-methyl-5-hepten2-ol & 953 & Musty, moldy, earthy & 2 & 0.001 & $0.011 \mathrm{a}$ & $0.017 \mathrm{a}$ & $0.026 \mathrm{a}$ & 0.032 \\
\hline 2-ethylhexanol & 985 & Rose, green & $0.83-1.5$ & 0.00135 & $0.00166 \mathrm{a}$ & $0.00023 \mathrm{~b}$ & $0 \mathrm{~b}$ & 0.0004 \\
\hline Linalool & 1050 & Flower, lavender & 0.006 & 0.0022 & $0.0036 \mathrm{a}$ & $0.0028 \mathrm{~b}$ & $0.0036 \mathrm{a}$ & 0.0005 \\
\hline Phenylethanol $^{\mathrm{w}}$ & 1075 & Honey, spice, rose, lilac & $1.0-1.1$ & 1.45 & $3.04 \mathrm{a}$ & $1.85 \mathrm{~b}$ & $1.32 \mathrm{~b}$ & 0.54 \\
\hline \multicolumn{9}{|l|}{ Ketones } \\
\hline 2-butanone & 589 & Sweet & 7 & 0.028 & $0.033 \mathrm{a}$ & $0.021 \mathrm{a}$ & $0.027 \mathrm{a}$ & 0.013 \\
\hline 1-penten-3-one ${ }^{\mathrm{w}}$ & 663 & Fruit, floral, green & 0.0015 & 0.013 & $0.0131 \mathrm{a}$ & $0.0048 \mathrm{~b}$ & $0.0098 \mathrm{a}$ & 0.0038 \\
\hline 6-methyl-5-hepten2-one ${ }^{\mathrm{w}}$ & 946 & Pepper, mushroom, rubber & 0.05 & 0.24 & $0.40 \mathrm{a}$ & $0.34 \mathrm{a}$ & $0.27 \mathrm{a}$ & 0.13 \\
\hline 2-ethylfuran & 675 & Rum, coffee, and chocolate & - & 0.0141 & $0.0061 \mathrm{a}$ & $0.0036 \mathrm{~b}$ & $0.0026 \mathrm{~b}$ & 0.0012 \\
\hline \multicolumn{9}{|l|}{ Sulfur compounds } \\
\hline 2-isobutylthiazole ${ }^{\mathrm{w}}$ & 999 & Tomato leaf, green & 0.0035 & 0.0028 & $0.0046 \mathrm{a}$ & $0.0040 \mathrm{a}$ & $0.0047 \mathrm{a}$ & 0.0055 \\
\hline Dimethyl disulfide & 722 & Onion, cabbage, putrid & 0.012 & 0.00049 & $0.00180 \mathrm{a}$ & $0.00099 \mathrm{a}$ & $0.00208 \mathrm{a}$ & 0.0026 \\
\hline Ester & & & & & & & & \\
\hline 2-methybutyl acetate & 843 & Fruit & $0.005-0.011$ & 0.00284 & $0.00093 \mathrm{a}$ & $0.00106 \mathrm{a}$ & $0.00085 \mathrm{a}$ & 0.0003 \\
\hline $\begin{array}{l}\text { Nitrogen- and oxygen-containin } \\
\text { compounds }\end{array}$ & & & & & & & & \\
\hline 1-nitropentane & 913 & Pleasant, fruity & 22 & 0.0023 & $0.0062 \mathrm{a}$ & $0.00074 \mathrm{~b}$ & $0 \mathrm{~b}$ & 0.02 \\
\hline Overall & & & & & & & & \\
\hline Total aldehydes & & & & 10.67 & $12.55 \mathrm{a}$ & $2.45 \mathrm{c}$ & $4.24 \mathrm{~b}$ & 1.37 \\
\hline Total alcohols & & & & 2.45 & $4.47 \mathrm{a}$ & $2.72 \mathrm{~b}$ & $1.83 \mathrm{c}$ & 0.6 \\
\hline Total ketones & & & & 0.29 & $0.51 \mathrm{a}$ & $0.38 \mathrm{a}$ & $0.34 \mathrm{a}$ & 0.16 \\
\hline Total hydrocarbons & & & & 0.584 & $0.091 \mathrm{~b}$ & $0.145 \mathrm{a}$ & $0.038 \mathrm{c}$ & 0.027 \\
\hline Total oxygen-containing & & & & & & & & \\
\hline heterocyclic compounds & & & & 0.022 & $0.026 \mathrm{a}$ & $0.011 \mathrm{c}$ & $0.018 \mathrm{~b}$ & 0.004 \\
\hline Total sulfur compounds & & & & 0.0033 & $0.0064 \mathrm{a}$ & $0.0050 \mathrm{a}$ & $0.0068 \mathrm{a}$ & 0.007 \\
\hline Total esters & & & & 0.00284 & $0.00093 \mathrm{a}$ & $0.00106 \mathrm{a}$ & $0.00085 \mathrm{a}$ & 0.0003 \\
\hline Total nitrogen- and oxygen- & aining & & & & & & & \\
\hline compounds & & & & 0.0023 & $0.0062 \mathrm{a}$ & $0.00074 \mathrm{~b}$ & $0 \mathrm{~b}$ & 0.02 \\
\hline Total volatile compounds & & & & 14.02 & $17.66 \mathrm{a}$ & $5.71 \mathrm{~b}$ & $6.47 \mathrm{~b}$ & 1.72 \\
\hline
\end{tabular}

${ }^{2}$ Three different treatments are untreated control, $5^{\circ} \mathrm{C}$ air chilling for $4 \mathrm{~d}$, and $50{ }^{\circ} \mathrm{C}$ hot water blanching for $5 \mathrm{~min}$.

${ }^{y}$ Odor descriptions of 6-methyl-5-hepten-2-one and geranylacetone were adapted from Klee (2010), while others from Acree and Arn (2010).

${ }^{\mathrm{x}}$ Odor threshold values in water were adapted from van Gemert (2003).

${ }^{\text {wV}}$ Volatile compounds that were considered by Klee and Giovannoni (2011) and Tandon et al. (2001) to have an contribution to tomato aroma.

vData presented were the mean values of five biological replicates. Mean values that are not followed by the same letter within the same row show significant difference using Duncan's multiple range test $(P<0.05)$.

LSD, least significant differences. 
$20 \mathrm{~min}$ at $12,000 \mathrm{~g}$ at $4{ }^{\circ} \mathrm{C}\left(\mathrm{Avanti}^{\circledR} \mathrm{J}-\mathrm{E}\right.$ centrifuge; Beckman Coulter), and the supernatant was collected as the crude enzyme source containing all isozymes and assayed immediately or flash-frozen in liquid nitrogen and stored at $-80{ }^{\circ} \mathrm{C}$ until analysis.

The substrate for HPL was prepared according to Vick (1991), but was neither purified nor was the purity measured. The assay mixture included $60 \mu \mathrm{L}$ of $0.1 \mathrm{M}$ sodium phosphate $(\mathrm{pH}$ 6.7) buffer, $10 \mu \mathrm{L}$ of $1 \mathrm{~mm} \mathrm{NADH}, 10 \mu \mathrm{L}$ of $150 \mathrm{U}$ yeast ADH solution, $90 \mu \mathrm{L}$ of substrate, and $60 \mu \mathrm{L}$ of the extract. First, the background oxidation rate of NADH was measured in the absence of enzyme (HPL), then the HPL was added and the reaction was continued for $15 \mathrm{~min}$ at $20^{\circ} \mathrm{C}$ by following a decrease in absorbance at $340 \mathrm{~nm}$. The net HPL activity excluded background oxidation and was expressed as the amount of enzyme consuming $1 \mathrm{nmol}$ of substrate or NADH in $1 \mathrm{~min}$ (Froehlich et al., 2001; Vick, 1991). An extinction coefficient of $6.2 \mathrm{~mm}^{-1} \cdot \mathrm{cm}^{-1}$ was used for the calculation.

Protein determination was carried out based on the Bradford (1976) method (protein assay kit; BioRad, Hercules, CA) using a microtiter plate assay, as per the instructions of the manufacturer. A calibration curve was determined with $\operatorname{IgG}$ (bovine plasma gamma globulin) as the protein standard. HPL activity was expressed as $\mathrm{mmol} \cdot \mathrm{s}^{-1} \cdot \mu \mathrm{g}^{-1}$

Statistical analysis. Data presented were the mean values of five biological replicates for volatile compounds. SAS Version 9.3 (SAS Institute, Cary, NC) was used to analyze the data, using analysis of variance [ANOVA (PROC ANOVA)]. Mean separation was determined by Duncan's multiple range test at the 0.05 level, followed by the analysis of the least significant differences (LSD) for each compound. For multivariate statistical analyses, principal component analysis (PCA) and average linkage cluster analysis (CA) were performed using JMP (SAS Institute). For e-nose data analysis, the manufacturer's statistical program, AlphaSOFT (Alpha MOS), was used. Principal component analysis (PCA), discrimination power of auto-selected sensors, and distance and pattern discrimination index between samples were analyzed.

\section{Results and Discussion}

Volatile components detected in full ripe ' $F L$ 47' tomatoes. A total of 42 aromatic volatile compounds were detected by HSSPME-GC-MS, belonging to eight chemical classes, including 17 aldehydes, 11 alcohols, 4 ketones, 4 hydrocarbons, 2 oxygen-containing heterocyclic compounds, 2 sulfur compounds, 1 ester, and 1 nitrogen- and oxygen-containing heterocyclic compound (Table 1). The most abundant compounds (in order of concentration) were 2-phenylacetaldehyde, trans, trans-2, 4-hexadienal, 2-phenylethanol, trans-2-hexenal, and 2-methylbutanal (Table 1). Aldehydes composed the largest percentage of the total volatile concentration, followed by alcohols and ketones, and the top three compound classes constituted more than $99 \%$ of total volatile concentration. Table 1 lists all the volatile compounds along with their classifications, retention indexes, odor descriptions, and odor thresholds in water.

Of those, 17 aromatic volatile compounds, which were reportedly present at a level of $>1 \mathrm{ng} \cdot \mathrm{L}^{-1}$ in tomato fruit (Buttery, 1993) and considered by Klee and Giovannoni (2011) and Tandon et al. (2001) to have a contribution to tomato aroma, were identified in 'FL 47' tomatoes in this study, including pentanal, pentanol, 1-penten-3-one, cis-3-hexenal, hexanal, trans-2-hexenal, 6-methyl-5-hepten-2-one, geranylacetone, geranial, 2-methylbutanal, 2-methylbutanol, 3-methylbutanal, 3-methylbutanol, 2-isobutylthiazole, 2-phenylacetaldehyde, 2-phenylethanol, and benzaldehyde (Table 1). In tomato, they are derived from different precursors: 6-methyl-5-hepten-2-one, geranylacetone, and geranial are synthesized from carotenoids; fatty acids are the precursors for pentanal, pentanol, 1-penten-3-one, cis-3-hexenal, hexanal, and trans-2-hexenal; on the other hand, 2-methylbutanal, 2-methylbutanol, 3-methylbutanal, 3-methylbutanol, 2-isobutylthiazole, 2-phenylacetaldehyde, 2-phenylethanol, and benzaldehyde are amino acid derivatives. In tomato fruit, 2-methylbutanal, 2-methylbutanol, 3-methylbutanal, 3-methylbutanol, and 2-isobutylthiazole are derived from branched-chain amino acid, while 2-phenylacetaldehyde, 2-phenylethanol, and benzaldehyde are synthesized from phenylalanine. Except for pentanol, 3-methylbutanol, geranial, and benzaldehyde, the concentrations of other 13 volatile compounds in control fruit were higher than reported odor thresholds in water (Table 1).

Response of volatile production to refrigeration. Refrigerated tomatoes did not cause any visual CI symptoms during 4 -d storage at $5{ }^{\circ} \mathrm{C}$. However, 25 out of the 42 aroma compounds were greatly suppressed by the refrigeration with a reduction of total volatile concentration by $68 \%$ (Table 1). The greatest reduction occurred in nitrogen- and oxygen-containing heterocyclic compound with an $88 \%$ loss, followed by aldehydes $(80 \%)$, oxygen-containing heterocyclic compounds (58\%), and alcohols (39\%) (Table 1).

Of the 17 important compounds, compared with that of the control, refrigeration inhibited the abundance of cis-3-hexenal, hexanal, and trans-2-hexenal by $89 \%, 74 \%$, and $93 \%$, respectively. Such reduction might be due to the lower activity of HPL, which is a key enzyme for their biosynthesis (Wang et al., 2015b). This results were inconsistent with the report of Renard et al. (2013) that associated reduced HPL activity with refrigeration of red-ripe tomatoes at $4{ }^{\circ} \mathrm{C}$ for $6 \mathrm{~d}$ and decreased the production of $\mathrm{cis}$-3-hexenal, hexanal, and trans-2-hexenal. As shown in Fig. 1, after refrigeration HPL activity reduced to only $53 \%$ of that in control fruit. On the other hand, three straight carbon 5 volatile compounds, including pentanal, pentanol, and 1-penten-3-one, were also inhibited after refrigeration by $79 \%, 93 \%$, and $63 \%$, respectively (Table 1 ). Their biopathway is less clear until recently when Shen et al. (2014) found the involvement of TomloxC in their biosynthesis. Previously, McDonald et al. (1999) found that 14-d exposure of mature green tomato to $2{ }^{\circ} \mathrm{C}$ before ripening at $20{ }^{\circ} \mathrm{C}$ significantly suppressed the abundance of 1-penten-3-one and 6-d refrigeration of red-ripe tomatoes at $4{ }^{\circ} \mathrm{C}$ greatly reduced the production of pentanol and 1-penten-3-one (Renard et al., 2013). For apocarotenoid volatile, refrigeration substantially reduced the productions of geranial and geranylacetone by $32 \%$ and $89 \%$, respectively (Table 1). Previously, Renard et al. (2013) found that the abundance of geranial and geranylacetone exhibit $44 \%$ and $66 \%$ reduction, respectively, in red-ripe ' $\mathrm{LCx}$ ' tomato fruits. Carotenoid derived volatiles are characterized as "fruity/floral" and are important contributors to tomato aroma (Klee, 2010). Their production correlates strongly with the levels of their direct precursor carotenoid compositions (Lewinsohn et al., 2005). During low temperature stress, the synthesis of carotenoids is downregulated (Rugkong et al., 2011). Thus in our study, the reduction of geranylacetone and geranial after refrigeration might be due to the reduced contents of the carotenoid precursors, which constrained production downstream. For branched-chain amino acid-derived volatiles, in agreement with Renard et al. (2013) results low temperature storage greatly suppressed the production of 3-methylbutanal, 2-methylbutanal, and 3-methylbutanol by $59 \%$, $72 \%$, and $58 \%$, respectively, which are reported to impart fruit "malt" aroma notes (Table 1). In tomato, the first and ratelimiting step for their biosynthesis is hypothesized to be catalyzed by branched-chain aminotransferases (BCATs), which remove the amino groups from the respective amino acids (Kochevenko et al., 2012). In banana fruit, high expression level of BanBCAT is correlated to higher production of branchedchain volatiles (Yang et al., 2011). So in our study, the lower branched-chain volatiles after refrigeration is possibly due to the downregulated enzyme activities of specific BCAT isomers involved in their biosynthesis. Furthermore, two phenolic volatiles, 2-phenylacetaldehyde and 2-phenylethanol, which are described as "floral," "fruity," and "rose like" notes, were also suppressed after refrigeration by $60 \%$ and $39 \%$, respectively (Table 1). The key regulator for their production is aromatic amino acid decarboxylases (AADCs) activity (Wang et al., 2015b). During low temperature stress, a higher activity of phenylalanine ammonialyase (PAL), which shares a substrate with AADCs, is induced in tomato fruit (Rhodes and Wooltorton, 1977). PAL is suggested to be involved in the biosynthesis of methyl salicylate (Rambla et al., 2014), which plays 


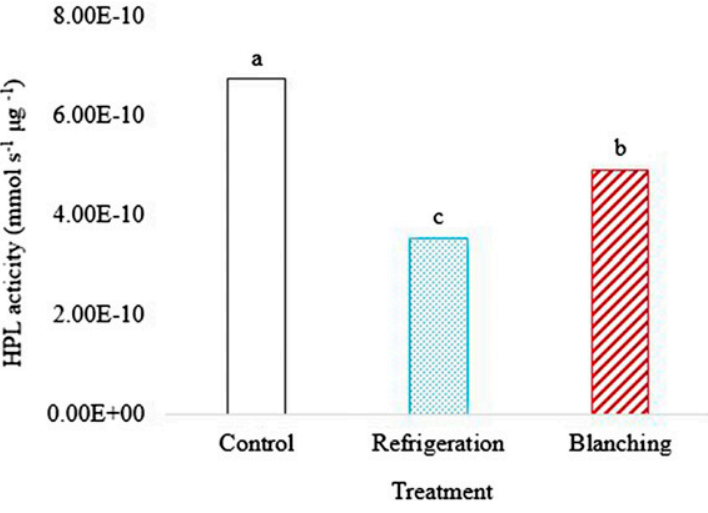

Fig. 1. Impact of refrigeration and blanching on enzyme activity of hydroperoxide lyase (HPL) in full ripe 'FL 47 ' tomato fruits. Three different treatments were untreated control, $5^{\circ} \mathrm{C}$ air chilling for $4 \mathrm{~d}$, and $50{ }^{\circ} \mathrm{C}$ hot water for $5 \mathrm{~min}$. Vertical bars labeled with the different letters are significantly different at $P<0.05$ level by using Duncan's multiple range test. LSD $=1.084 \mathrm{E}-10$.

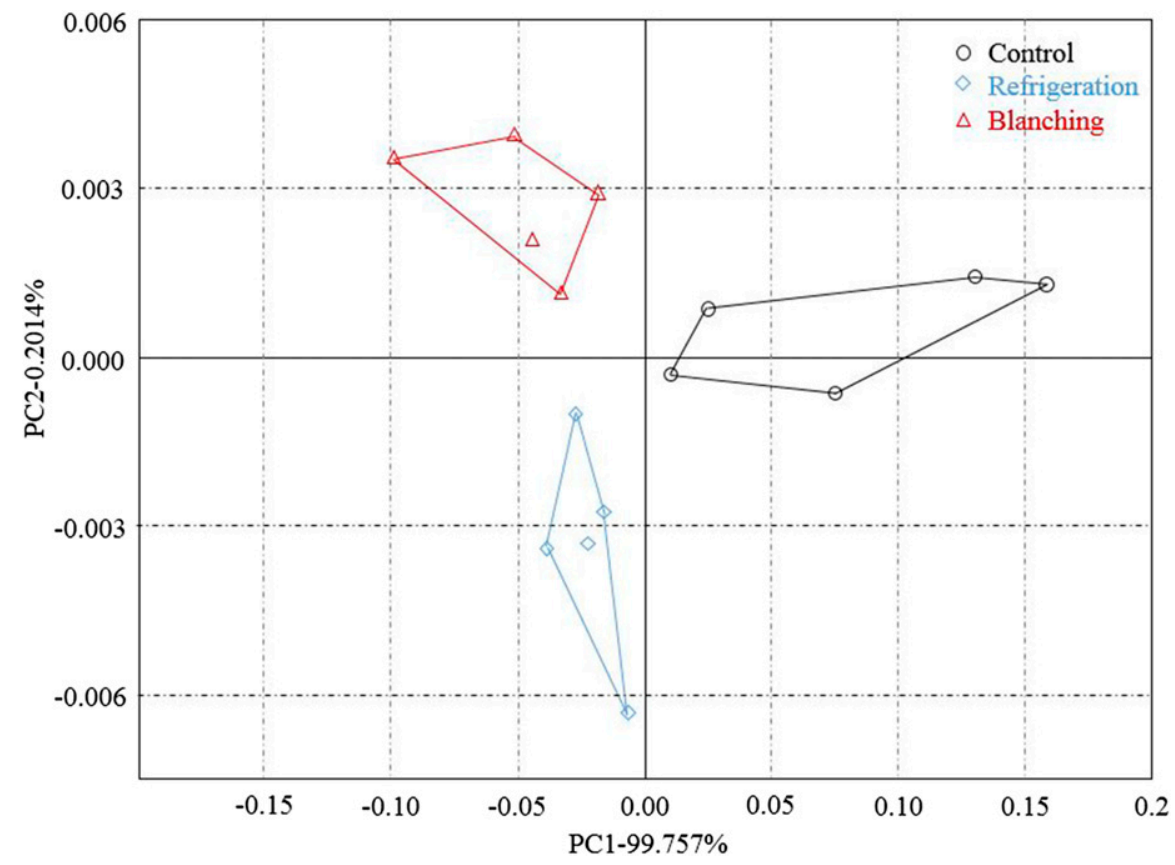

Fig. 2. Principal component analysis (PCA) of e-nose data of full ripe 'FL 47 ' tomato fruits after refrigeration and blanching treatments. Three different treatments are untreated control, $5^{\circ} \mathrm{C}$ air for $4 \mathrm{~d}$ and $50{ }^{\circ} \mathrm{C}$ hot water for $5 \mathrm{~min}$.

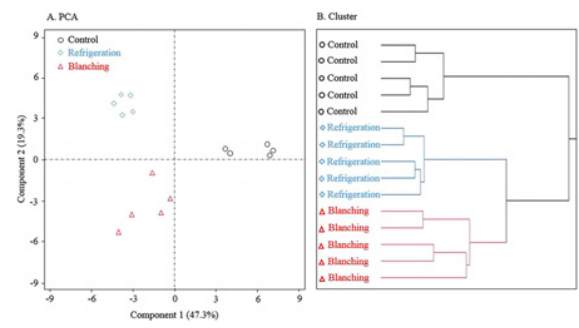

Fig. 3. Principle component analysis (PCA) and cluster analysis (CA) of 42 aromatic volatile compounds detected by HS-SPME-GC-MS in full ripe ' $\mathrm{FL} 47$ ' tomato fruits after refrigeration and blanching treatments. Three different treatments were untreated control, $5{ }^{\circ} \mathrm{C}$ air chilling for $4 \mathrm{~d}$, and $50^{\circ} \mathrm{C}$ hot water for $5 \mathrm{~min}$.

an important role in imparting tomato fruit cold resistance (Fung et al., 2004). It is assumed that chilling enhanced PAL activity, resulting in lower substrate availability, is responsible for lower levels of 2-phenylacetaldehyde and 2-phenylethanol in our study (Wang et al., 2015b). A similar trend of 2-phenylacetaldehyde and 2-phenylethanol in tomatoes after refrigeration was found by Renard et al. (2013).

E-nose, which acts as an alternative objective method to determine differences in volatile profiles by calculated patterns based on responses of electronic sensors, has been considered as a replacement for panelists in quality control for ease of analysis, reproducibility, and convenience, although various factors such as room temperature, light, humidity, and static electricity can affect the quality of data obtained (Baldwin et al., 2011; Raithore et al., 2014). Because the basic underlying principle behind e-nose and human smell perception is similar, electronic nose with its eighteen sensors (LY2/LG, LY2/G, LY2/AA, LY2/GH, LY2/
gCT1, LY2/gCT, T30/1, P10/1, P10/2, P40/1, $\mathrm{T} 70 / 2, \mathrm{PA} / 2, \mathrm{P} 30 / 1, \mathrm{P} 40 / 2, \mathrm{P} 30 / 2, \mathrm{~T} 40 / 2$, $\mathrm{T} 40 / 1$, and $\mathrm{TA} / 2$ ) and data processing component, can discriminate one set of samples from another with different volatile profiles (Tan et al., 2001).

Five sensors (LY2/LG, LY2/G, LY2/AA, $\mathrm{LY} 2 / \mathrm{GH}$, and $\mathrm{LY} 2 / \mathrm{gCTl}$ ) were selected by using the AlphaSOFT sensor optimization procedure in the software and the raw data. For further simplification of the data and to extract relevant information, PCA was conducted based on covariance (Fig. 2). As a result, the first principal component explained more than $99 \%$ of the data variability, and separated refrigerated samples from controls (Fig. 2), with a Mahalanobis distance of 0.13 (McLachlan, 2004).

To clarify the relationship between GCMS and e-nose results, PCA and cluster analysis were performed using 42 volatile data. Figure $3 \mathrm{~A}$ shows the projection on the main first two principle components revealing in total $66.6 \%$ (47.3\% on PC1 and $19.3 \%$ on PC2) of the total aroma variation. The score plot shows the position of the replicate samples inside the reduced aroma space as defined by PC1 and PC2, with their mutual distances reflecting the differences in their volatility. Refrigerated tomatoes were separated from the control fruit along PC1 indicating a clear difference in their volatility accounting for $47.3 \%$ of the total variability (Fig. 3A) Hierarchical cluster analysis using average linkage showed that control samples are separated from refrigerated samples when dividing the data into two groups (Fig. 3B). These results were in agreement with the e-nose result (Fig. 2).

Response of volatile production to blanching. Similar to refrigeration treatment, although no visual injury was observed on fruit after blanching, PCA analysis based on e-nose data and GC-MS results separated the blanched samples from control along with PC1 (Figs. 2 and 3A); and the Mahalanobis distance between control and branched fruit is 0.11 . Twenty-two out of 42 volatile compounds were greatly reduced by blanching, with the most reduction in nitrogen- and oxygen-containing heterocyclic compounds $(100 \%)$, followed by aldehydes $(66 \%)$, alcohols (59\%), hydrocarbons (58\%), and oxygen-containing heterocyclic compounds (31\%) (Table 1). Furthermore, blanching significantly inhibited HPL activity of tomatoes by $24 \%$ (Fig. 1 ).

Of the 17 important compounds, cis-3hexenal and trans-2-hexenal were reduced after blanching by $47 \%$ and $54 \%$, respectively (Table 1), which might be due to the downregulated HPL activity (Fig. 1). Similar to refrigeration, PAL activity in tomato accumulates after high temperature stress (Rivero et al., 2001), which might be responsible for reduced abundances of 2-phenylacetaldehyde and 2-phenylethanol in blanched fruits by $71 \%$ and $57 \%$, respectively (Table 1 ). In agreement with the result of Boukobza and 
Taylor (2002), in our study, the production of 2-methylbutanal and 2-methylbutanol were significantly inhibited by blanching to $38 \%$ and $58 \%$, respectively, of those in control fruits (Table 1). Blanching also reduced the levels of pentanal and pentanol by $57 \%$ and $100 \%$, respectively (Table 1). Although the mechanism for such reduction was unclear, previously a decrease of pentanol after high temperature stress was observed in cherry tomato (Viljanen et al., 2011).

Comparison of volatile profiles in refrigerated and blanched fruits. Both refrigeration and blanching significantly inhibited the volatile production in tomato fruit; however, there are different volatile profiles produced by the two different treatments. As shown in Figs. 2 and 3, both PCA and cluster analysis based on the results of GC-MS, as well as the PCA for e-nose analysis, discriminated the volatile profiles between refrigerated fruit and blanched fruit. Table 1 showed that in comparison with refrigerated fruits, blanched fruits had higher concentrations of aldehydes and oxygen-containing heterocylic compounds including 3-methylbutanal, pentanal, 2-methyl-2-butenal, cis-3-hexenal, hexanal, trans-2-hexenal, trans, trans-2, 4-hexadienal, 3-methylbutanol, 4-methylpentanol, linalool, 1-penten-3-one, geranial, and 2-methylfuran. On the other hand, the abundance of alcohols and hydrocarbons including 2-methylpropanol, 2-methylbutanol, 3-methylpentanol, $\alpha$-pinene, and d-limonene were significantly higher in refrigerated fruits than in blanched fruits (Table 1). On the other hand, the difference in HPL activity between blanched and refrigerated fruits was also significant although the latter was more affected (Fig. 1).

In conclusion, this study provides evidence that kitchen practices, storage of fruit in a refrigerator or a short blanching for sanitation substantially influenced volatile profile and reduced key tomato aroma contributors in full ripe tomato fruit. Low temperature storage resulted in a more severe impact than hot water blanching, especially in the reduction of carbon 6 aldehydes.

\section{Literature Cited}

Acree, T. and H. Arn. 2010. Flavornet and human odor space. Gas chromatography-olfactometry (GCO) of natural products. Cornell University, Ithaca, NY. 18 May 2015. <http://www.flavornet. org/flavornet.html>.

Bai, J., E.A. Baldwin, Y. Imahori, I. Kostenyuk, J. Burns, and J.K. Brecht. 2011. Chilling and heating may regulate $\mathrm{C} 6$ volatile aroma production by different mechanisms in tomato (Solanum lycopersicum) fruit. Postharvest Biol. Technol. 60:111-120.

Bai, J., E.A. Baldwin, R.C. Soliva Fortuny, J.P. Mattheis, R. Stanley, C. Perera, and J.K. Brecht. 2004. Effect of pretreatment of intact 'Gala' apple with ethanol vapor, heat, or 1-methylcyclopropene on quality and shelf life of fresh-cut slices. J. Amer. Soc. Hort. Sci. 129:583-593.

Baldwin, E.A., J. Bai, A. Plotto, R. Cameron, G. Luzio, J. Narciso, J. Manthey, W. Widmer, and B.L. Ford. 2012. Effect of extraction method on quality of orange juice: Hand-squeezed, commercial-fresh squeezed and processed. J. Sci. Food Agr. 92:2029-2042.

Baldwin, E.A., J. Bai, A. Plotto, and S. Dea. 2011. Electronic noses and tongues: Applications for the food and pharmaceutical industries. Sensors (Basel Switzerland) 11:4744-4766.

Baldwin, E.A., A. Plotto, J. Manthey, G. McCollum, J. Bai, and M. Irey. 2009. Effect of Liberibacter infection (Huanglongbing disease) of citrus on orange fruit physiology and fruit/fruit juice quality: Chemical and physical analyses. J. Agr. Food Chem. 58:1247-1262.

Baldwin, E.A., J.W. Scott, C.K. Shewmaker, and W. Schuch. 2000. Flavor trivia and tomato aroma: Biochemistry and possible mechanisms for control of important aroma components. HortScience 35:1013-1022.

Boukobza, F. and A.J. Taylor. 2002. Effect of postharvest treatment on flavour volatiles of tomatoes. Postharvest Biol. Technol. 25:321331.

Bradford, M.M. 1976. A rapid and sensitive method for the quantitation of microgram quantities of protein utilizing the principle of protein-dye binding. Anal. Biochem. 72:248254.

Buttery, R. 1993. Quantitative and sensory aspects of flavor of tomato and other vegetables and fruits, p. 259-286. In: T. Acree and R. Teranishi (eds.). Flavor science: Sensible principles and techniques. ACS, Washington, DC.

Castro, S.M., J.A. Saraiva, J.A. Lopes-da-Silva, I Delgadillo, A. Van Loey, C. Smout, and M. Hendrickx. 2008. Effect of thermal blanching and of high pressure treatments on sweet green and red bell pepper fruits (Capsicum annuum L.). Food Chem. 107:1436-1449.

Chun, O.K., D.O. Kim, N. Smith, D. Schroeder, J.T. Han, and C.Y. Lee. 2005. Daily consumption of phenolics and total antioxidant capacity from fruit and vegetables in the American diet. J. Sci. Food Agr. 85:1715-1724.

de Castro, L.R., L.A. Cortez, and C. Vigneault. 2006. Effect of sorting, refrigeration and packaging on tomato shelf life. J. Food Agr. Environ. 4:70-74.

Ding, C-K., C. Wang, K.C. Gross, and D.L. Smith. 2002. Jasmonate and salicylate induce the expression of pathogenesis-related-protein genes and increase resistance to chilling injury in tomato fruit. Planta 214:895-901.

El Hadi, M.A.M., F-J. Zhang, F-F. Wu, C-H. Zhou, and J. Tao. 2013. Advances in fruit aroma volatile research. Molecules 18:8200-8229.

Froehlich, J.E., A. Itoh, and G.A. Howe. 2001. Tomato allene oxide synthase and fatty acid hydroperoxide lyase, two cytochrome P450s involved in oxylipin metabolism, are targeted to different membranes of chloroplast envelope. Plant Physiol. 125:306-317.

Fung, R.W., C.Y. Wang, D.L. Smith, K.C. Gross, and M. Tian. 2004. MeSA and MeJA increase steady-state transcript levels of alternative oxidase and resistance against chilling injury in sweet peppers (Capsicum annuиm L.). Plant Sci. 166:711-719.

Gross, K.C., C.Y. Wang, and M. Saltveit. 2004. The commercial storage of fruits, vegetables, and florist and nursery stocks. An Adobe Acrobat pdf of a draft version of the forthcoming revision to U.S. Department of Agriculture, Agriculture Handbook 66 on the website of the USDA, Agricultural Research Service, Beltsville, MD. 18 May 2015. $<\mathrm{http}: / /$ www.ba.ars.usda.gov/hb66/>.

Guil-Guerrero, J. and M. Rebolloso-Fuentes. 2009. Nutrient composition and antioxidant activity of eight tomato (Lycopersicon esculentum) varieties. J. Food Compos. Anal. 22:123-129.

Hirayama, K. $2012.50^{\circ} \mathrm{C}$ waching and dipping. 1st ed. Shufunotomo, Tokyo, Japan.

Klee, H.J. 2010. Improving the flavor of fresh fruits: Genomics, biochemistry, and biotechnology. New Phytol. 187:44-56.

Klee, H.J. and J.J. Giovannoni. 2011. Genetics and control of tomato fruit ripening and quality attributes. Annu. Rev. Genet. 45:41-59.

Kochevenko, A., W.L. Araújo, G.S. Maloney, D.M. Tieman, P.T. Do, M.G. Taylor, H.J. Klee, and A.R. Fernie. 2012. Catabolism of branched chain amino acids supports respiration but not volatile synthesis in tomato fruits. Mol. Plant 5:366-375.

Lewinsohn, E., Y. Sitrit, E. Bar, Y. Azulay, A. Meir, D. Zamir, and Y. Tadmor. 2005. Carotenoid pigmentation affects the volatile composition of tomato and watermelon fruits, as revealed by comparative genetic analyses. J. Agr. Food Chem. 53:3142-3148.

Luengwilai, K. and D.M. Beckles. 2010. Climacteric ethylene is not essential for initiating chilling injury in tomato (Solanum lycopersicum) cv. Ailsa Craig. J. Stored Prod. Postharvest Res. 1:1-8.

Lurie, S. 1998. Postharvest heat treatments. Postharvest Biol. Technol. 14:257-269.

Maul, F., S. Sargent, C. Sims, E. Baldwin, M. Balaban, and D. Huber. 2000. Tomato flavor and aroma quality as affected by storage temperature. J. Food Sci. 65:1228-1237.

McDonald, R., T. McCollum, and E. Baldwin. 1996. Prestorage heat treatments influence free sterols and flavor volatiles of tomatoes stored at chilling temperature. J. Amer. Soc. Hort. Sci. 121:531-536.

McDonald, R., T. McCollum, and E. Baldwin. 1999. Temperature of water heat treatments influences tomato fruit quality following lowtemperature storage. Postharvest Biol. Technol. 16:147-155.

McLachlan, G. 2004. Discriminant analysis and statistical pattern recognition. 2nd ed. John Wiley \& Sons, Inc., Hoboken, NJ.

Plotto, A., J. Bai, E.A. Baldwin, and J.K. Brecht. 2003. Effect of pretreatment of intact 'Kent' and 'Tommy Atkins' mangoes with ethanol vapor, heat or 1-methylcyclopropene on quality and shelf life of fresh-cut slices. Proc. Fla. State Hort. Soc. 116:394-400.

Raithore, S., S. Dea, A. Plotto, J. Bai, J. Manthey, J. Narciso, M. Irey, and E. Baldwin. 2014. Effect of blending Huanglongbing (HLB) disease affected orange juice with juice from healthy orange on flavor quality. Lwt-Food Sci. Technol. 62:868-874.

Rambla, J.L., Y.M. Tikunov, A.J. Monforte, A.G. Bovy, and A. Granell. 2014. The expanded tomato fruit volatile landscape. J. Expt. Bot. 65:4613-4623.

Renard, C.M., C. Ginies, B. Gouble, S. Bureau, and M. Causse. 2013. Home conservation strategies for tomato (Solanum lycopersicum): Storage temperature vs. duration-Is there a compromise for better aroma preservation? Food Chem. 139:825-836.

Rhodes, M.J. and L.S. Wooltorton. 1977. Changes in the activity of enzymes of phenylpropanoid metabolism in tomatoes stored at low temperatures. Phytochemistry 16:655-659.

Rivero, R.M., J.M. Ruiz, P.C. Garcia, L.R. LopezLefebre, E. Sánchez, and L. Romero. 2001 Resistance to cold and heat stress: Accumulation of phenolic compounds in tomato and watermelon plants. Plant Sci. 160:315-321. 
Rugkong, A., R. McQuinn, J.J. Giovannoni, J.K. Rose, and C.B. Watkins. 2011. Expression of ripening-related genes in cold-stored tomato fruit. Postharvest Biol. Technol. 61:1-14.

Saltveit, M. and L. Morris. 1990. Overview on chilling injury of horticultural crops, p. 3-15. In: C.Y. Wang (ed.). Chilling injury in horticultural crops. CRC Press, Boca Raton, FL.

Shen, J., D. Tieman, J.B. Jones, M.G. Taylor, E. Schmelz, A. Huffaker, D. Bies, K. Chen, and H.J. Klee. 2014. A 13-lipoxygenase, TomloxC, is essential for synthesis of C5 flavour volatiles in tomato. J. Expt. Bot. 65:419-428.

Tan, T.T., V. Schmitt, O. Lucas, and S. Isz. 2001. Electronic noses and electronic tongues. LabPlus Internat. 13:16-19.

Tandon, K.S., M. Jordan, K.L. Goodner, and E.A. Baldwin. 2001. Characterization of fresh tomato aroma volatiles using GC-olfactometry. Proc. Fla. State Hort. Soc. 114:142-144.
Tieman, D., P. Bliss, L.M. McIntyre, A. BlandonUbeda, D. Bies, A.Z. Odabasi, G.R. Rodríguez, E. van der Knaap, M.G. Taylor, and C. Goulet. 2012. The chemical interactions underlying tomato flavor preferences. Curr. Biol. 22:1035-1039.

USDA. 1997. United States standards for grades of fresh tomatoes. 18 May 2015. <http://www. ams.usda.gov/AMSv1.0/getfile?dDocName= STELPRDC5050331>.

van Gemert, L. 2003. Odour thresholds-compilations of odour thresholds in air, water and other media, 1st ed. Oliemans Punter \& Partners BV, Utrecht, The Netherlands.

Vick, B.A. 1991. A spectrophotometric assay for hydroperoxide lyase. Lipids 26:315-320.

Viljanen, K., M. Lille, R-L. Heiniö, and J. Buchert. 2011. Effect of high-pressure processing on volatile composition and odour of cherry tomato purée. Food Chem. 129:1759-1765.
Wang, L., E.A. Baldwin, A. Plotto, W. Luo, S. Raithore, Z. Yu, and J. Bai. 2015a. Effect of methyl salicylate and methyl jasmonate pretreatment on the volatile profile in tomato fruit subjected to chilling temperature. Postharvest Biol. Technol. 108:28-38.

Wang, L., E.A. Baldwin, W. Zhao, A. Plotto, X. Sun, Z. Wang, J.K. Brecht, J. Bai, and Z. Yu. 2015 b. Suppression of volatile production in tomato fruit exposed to chilling temperature and alleviation of chilling injury by a prechilling heat treatment. Lwt-Food Sci. Technol. 62:115-121.

Yang, X., J. Song, S. Fillmore, X. Pang, and Z. Zhang. 2011. Effect of high temperature on color, chlorophyll fluorescence and volatile biosynthesis in green-ripe banana fruit. Postharvest Biol. Technol. 62:246-257. 